\title{
Prevalence of prehypertension and hypertension among jenukuruba tribal children in Mysore district
}

\author{
Narayanappa ${ }^{1}$, HS Rajani², K Jagadish Kumar ${ }^{3}$, VG. Manjunath ${ }^{4}$ \\ ${ }^{1}$ Dr D Narayanappa, Professor and Head, ${ }^{2}$ Dr HS Rajani, Assistant Professor, ${ }^{3}$ Dr K. Jagadish Kumar, Professor, ${ }^{4}$ Dr VG. \\ Manjunath, Associate Professor. All are affiliated with of Department of Pediatrics, JSS Medical College, JSS University; \\ Mysore, India.
}

Address for Correspondence: Dr. Rajani H. S, 1813, 4th Main, 6th Cross, F- Block, Kanakadasanagara, Mysore, Karnataka, India. Email:drrajanihs@gmail.com

\begin{abstract}
Introduction: Hypertension is a major public health problem found to have origin very early in life but remains asymptomatic warranting screening of all children. Objective: To study the prevalence of Pre hypertension and Hypertension among traditional Jenukuruba tribal children in Mysore district. Methods: Community based cross sectional study done over a period of 2 years from. About 3864 children between the age group of 2-15 years of Jenukuruba tribal community were enrolled in the study. Anthropometric measurements were recorded. Weight for age, Height for age and BMI were calculated. Blood pressure recording was done by research assistants and classified using American Heart Association fourth task force recommendations. Results: The point prevalence of systolic prehypertension and hypertension among tribal children between $2-15$ years was $6.9 \%$ and $2.3 \%$ respectively and the point prevalence of diastolic prehypertension and hypertension was $9.6 \%$ and $4.1 \%$ respectively. Conclusion: The prevalence of pre hypertension and hypertension in tribal children is similar and comparable to urban population.
\end{abstract}

Keywords: Children, Jenukuruba, Hypertension, Mysore, Tribal

\section{Introduction}

As India is undergoing rapid epidemiological transition, the burden of chronic diseases is increasing $[1,2,3,4]$. The fact that essential hypertension has its origin in childhood has resulted in increased emphasis on screening asymptomatic children [5,6,7]. According to 2001 census tribal population in India is 74.6 million (8.2\% of total population with 16 million tribal children (6-14years) among total 193 million children. Total population of tribal is 53 million in Karnataka which is $5.13 \%$ of Indian population. In Mysore district among 26, 41,027 tribal populations, Jenukuruba are the major tribal group [8].

However, few tribes and caste populations have been explored for such studies, in spite of India's diversity in terms of biological as well as sociocultural backgrounds [7]. Hence in our study we have made an attempt to study the prevalence of hypertension and prehypertension among Jenukuruba tribal children.

Manuscript received: $9^{\text {th }}$ December 2016

Reviewed: $17^{\text {th }}$ December 2016

Author Corrected: $24^{\text {th }}$ December 2016

Accepted for Publication: $31^{\text {st }}$ December 2016

\section{Methods}

This study was a community based cross sectional study with study population of about 3864 children between 215 years belonging to Jenukuruba community in Mysore district. Children were selected by purposive sampling method and predesigned proforma for data collection was used.

Preliminary site visit and enquiry of local officials and schools was done and all the Jenukuruba households mainly in H.D. kote, Hunsur, Nanjangud, Periyapatna were listed. Explanation was done in simple understandable language and consent was taken by parents for enrolment in the study. Institutional ethical committee approval was obtained.

Information regarding sociodemographic factors was collected by interview method using proforma. Anthropometry [height, weight, chest circumference, head circumference] were recorded by two research assistants under supervision of co-investigators using 
standard techniques. Anthropometric indices like weight for age, height for age, weight for height, BMI were calculated. WHO growth charts were used. Calibration of weighing machines, stadiometers, and measuring tapes are done periodically. Detailed clinical examination was done. Blood pressure recording was done by research assistants and classified using American Heart Association fourth task force

\section{Results}

Among 3864 tribal children enrolled under project, 1960 were males and 1904 were females with almost equal sex distribution.1175 (27.9\%) of children were having BMI $<5^{\text {th }}$ centile, $127(3.3 \%)$ children were overweight with BMI between $85^{\text {th }}$ and $95^{\text {th }}$ centile and $9(0.2 \%)$ children were obese with BMI $>95^{\mathrm{TH}}$ centile.

The point prevalence of systolic prehypertension and hypertension among tribal children between $2-15$ years was $6.9 \%$ and $2.3 \%$ respectively and the point prevalence of diastolic prehypertension and hypertension was $9.6 \%$ and $4.1 \%$ respectively. There was no statistically significant difference between boys and girls and also no statistically significant association with overweight and obesity.

Table-I: Age and sex distribution of study population.

\begin{tabular}{|c|c|c|c|}
\hline \multirow{2}{*}{$\begin{array}{c}\text { Age } \\
\text { (in yrs) }\end{array}$} & Male & Fex & \multirow{2}{*}{ Total } \\
\cline { 2 - 4 } & 239 & 258 & 497 \\
\hline $2-3$ & 461 & 453 & 914 \\
\hline $7-6$ & 495 & 437 & 932 \\
\hline $10-12$ & 425 & 429 & 854 \\
\hline $13-15$ & 340 & 327 & 667 \\
\hline Total & $\mathbf{1 9 6 0}$ & $\mathbf{1 9 0 4}$ & $\mathbf{3 8 6 4}$ \\
\hline
\end{tabular}

Figures in parenthesis indicate percentages. Among 3864 tribal children enrolled under project, 1960 were males and 1904 were females with equal sex distribution.

Table-II: Percentile classification of blood pressure in different age groups.

\begin{tabular}{|c|c|c|c|c|c|c|c|c|c|c|}
\hline \multirow{2}{*}{$\begin{array}{c}\text { Age (in } \\
\text { years) }\end{array}$} & \multicolumn{9}{|c|}{ Systolic } & \multicolumn{6}{c|}{ Diastolic } \\
\cline { 2 - 11 } & $\mathbf{N}$ & PREHTN & HTN & NC & Total & N & PREHTN & HTN & NC & Total \\
\hline $\mathbf{2 - 3}$ & $\begin{array}{c}457 \\
(12.29)\end{array}$ & $17(0.43)$ & $\begin{array}{c}04 \\
(0.10)\end{array}$ & $\begin{array}{c}1 \\
(0.02)\end{array}$ & $\begin{array}{c}497 \\
(12.8)\end{array}$ & $\begin{array}{c}300 \\
(7.76)\end{array}$ & $128(3.31)$ & $\begin{array}{c}68 \\
(1.75)\end{array}$ & $\begin{array}{c}1 \\
(0.02)\end{array}$ & $\begin{array}{c}497 \\
(12.8)\end{array}$ \\
\hline $\mathbf{4} 4-6$ & $\begin{array}{c}859 \\
(22.23)\end{array}$ & $39(1.00)$ & $\begin{array}{c}15 \\
(0.38)\end{array}$ & $\begin{array}{c}1 \\
(0.02)\end{array}$ & $\begin{array}{c}914 \\
(23.65)\end{array}$ & $\begin{array}{c}816 \\
(21.16)\end{array}$ & $79(2.04)$ & $\begin{array}{c}18 \\
(0.46)\end{array}$ & $\begin{array}{c}1 \\
(0.02)\end{array}$ & $\begin{array}{c}914 \\
(23.65)\end{array}$ \\
\hline $\mathbf{7 - 9}$ & $\begin{array}{c}830 \\
(21.4)\end{array}$ & $84(2.17)$ & $\begin{array}{c}18 \\
(0.46)\end{array}$ & - & $\begin{array}{c}932 \\
(24.12)\end{array}$ & $\begin{array}{c}857 \\
(22.17)\end{array}$ & $60(1.55)$ & $\begin{array}{c}15 \\
(0.38)\end{array}$ & - & $\begin{array}{c}932 \\
(24.12)\end{array}$ \\
\hline $\mathbf{1 0 - 1 2}$ & $\begin{array}{c}759 \\
(19.64)\end{array}$ & $62(1.60)$ & $\begin{array}{c}33 \\
(0.85)\end{array}$ & - & $\begin{array}{c}854 \\
(22.10)\end{array}$ & $\begin{array}{c}781 \\
(20.21)\end{array}$ & $39(1.00)$ & $\begin{array}{c}34 \\
(0.87)\end{array}$ & $-\begin{array}{c}24 \\
854 \\
(22.10)\end{array}$ \\
\hline $\mathbf{1 3 - 1 5}$ & $\begin{array}{c}582 \\
(15.06)\end{array}$ & $65(1.68)$ & $\begin{array}{c}20 \\
(0.51)\end{array}$ & - & $\begin{array}{c}667 \\
(17.26)\end{array}$ & $\begin{array}{c}576 \\
(14.90)\end{array}$ & $67(1.73)$ & $\begin{array}{c}24 \\
(0.62)\end{array}$ & $\begin{array}{c}667 \\
(17.26)\end{array}$ \\
\hline \multirow{2}{*}{ Total } & $\begin{array}{c}3505 \\
(90.7)\end{array}$ & $\mathbf{2 6 7 ( 6 . 9 0 )}$ & $\begin{array}{c}\mathbf{9 0} \\
(\mathbf{2 . 3 2})\end{array}$ & $\begin{array}{c}2 \\
(0.05)\end{array}$ & $\begin{array}{c}3864 \\
(100)\end{array}$ & $\begin{array}{c}3330 \\
(86.1)\end{array}$ & $\mathbf{3 7 3}(\mathbf{9 . 6 5})$ & $\begin{array}{c}\mathbf{1 5 9} \\
(\mathbf{4 . 1 1})\end{array}$ & $\begin{array}{c}2 \\
(0.05)\end{array}$ & $\begin{array}{c}3864 \\
(100)\end{array}$ \\
\hline
\end{tabular}

Figures in parenthesis indicate percentages

$N$ : normal $\left(<90^{\text {th }}\right.$ centile), PREHTN: prehypertension $\left(90^{\text {th }}-95^{\text {th }}\right.$ centile), HTN: hypertension $\left(>95^{\text {th }}\right.$ centile), NC: not cooperative. 
The point prevalence of systolic and diastolic prehypertension and hypertension among tribal children between 2-15 years was $6.9 \%, 2.3 \%$ and $9.6 \%, 4.1 \%$ respectively.

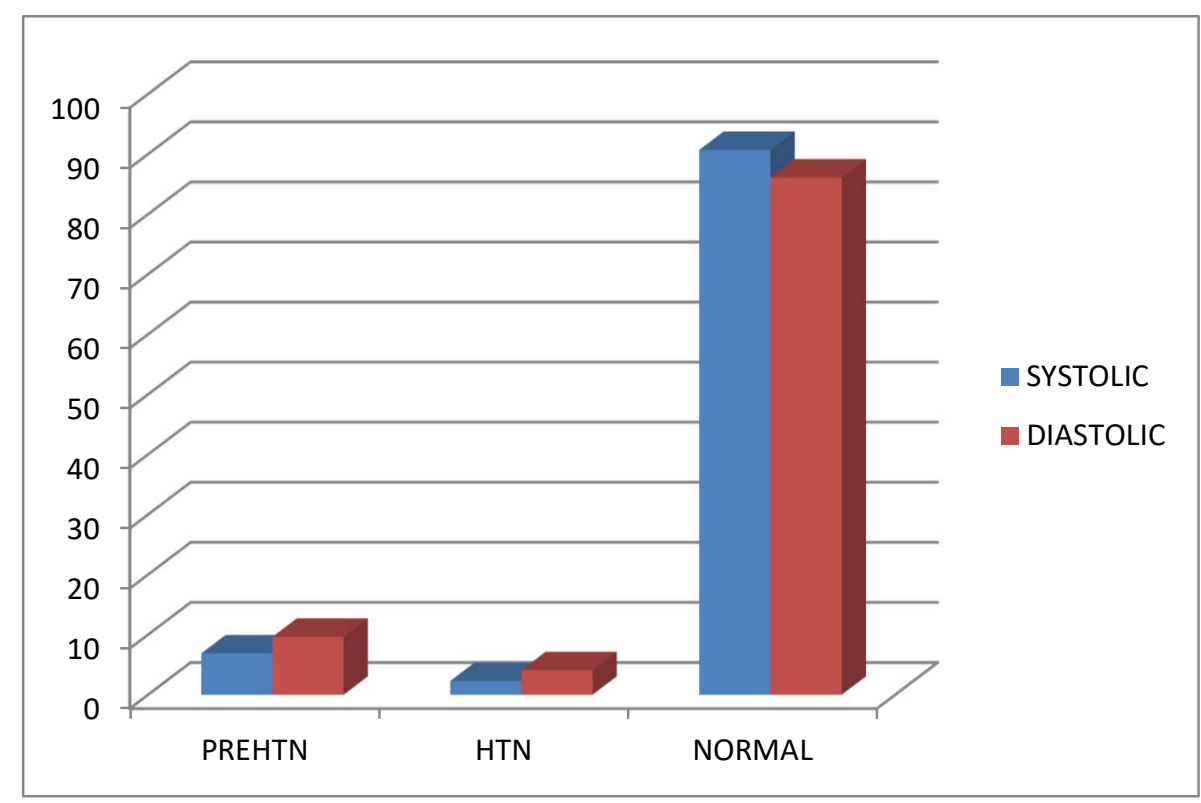

Fig-1: The point prevalence of prehypertension and hypertension in tribal children in percentage

\section{Discussion}

Hypertension is one of the major risk factors for cardiovascular and cerebrovascular diseases $[9,10]$. Increasing evidence indicates that essential hypertension begins to develop during the first two decades of life $[5,7]$.

It is important to determine the prevalence of prehypertension and hypertension in children to identify the population at risk as early identification leads to early interventions thereby preventing later morbidity and mortality.

There are very few data on prevalence of hypertension, prehypertension among tribal children in India. Throughout the world, low blood pressure $(<120 / 80 \mathrm{~mm} \mathrm{Hg})$ has been documented in adult tribal populations [11]. Similarly, in India, the traditional tribes and caste groups, which constitute a substantial percent of the country's population, are found to have lower BP than other ethnic groups [12]. Gradually, with changing social environment and lifestyle similar to other rural and urban population, marked increase in blood pressure has been noted [13].

However, few tribes and caste populations have been explored for such studies, in spite of India's diversity in terms of biological as well as sociocultural backgrounds. In our study we made an attempt to study the prevalence of hypertension, prehypertension in Jenukuruba tribal children in Mysore district.

The overall point prevalence of systolic prehypertension and hypertension among tribal children between 2-15 years was $6.9 \%$ and $2.3 \%$ respectively and the point prevalence of diastolic prehypertension and hypertension was $9.6 \%$ and $4.1 \%$ respectively which was comparable to the prevalence of prehypertension $(9.39 \%)$ and prevalence of hypertension $(2.62 \%)$ among rural Tripuri boys [7].

The prevalence of hypertension have been reported to have a wide range (1\%-16.2\%) among various studies $[4,10,14,15,16]$. The prevalence in tribal population believed to be less was on par with the prevalence of Hypertension and Pre hypertension among urban school children aged 5-15 years in Mysore district, which were $4.8 \%$ and $11 \%$ respectively [4].

The prevalence of Hypertension in children was between $5-10$ years was $4.1 \%$ and Pre hypertension was $4.8 \%$. In $11-15$ years age group it was $5.7 \%$ and $20.2 \%$ respectively. In another study done in Mysore district, Prevalence of pre-hypertension and hypertension was $2.9 \%$ and $2.8 \%$ in urban children and $2.8 \%$ and $2 \%$ in rural children respectively which was less compared to this study [16]. 
The prevalence of overweight and obesity in our study was $3.3 \%$ and $0.2 \%$, respectively which was little less compared to other school based data in India, which demonstrated prevalence of overweight and obesity in the range of $5.6 \%$ to $2.4 \%$ among children and adolescents $[1,7,17]$. The prevalence of overweight and obesity in a study done in urban school children of Mysore district was $11 \%$ and $4.4 \%$, respectively which was higher compared to the present study [4].

Various other studies have reported statistically significant association between hypertension and obesity $[1,7,17]$.

In our study, there was no statistically significant association between overweight, obesity and hypertension. There was no statistically significant difference in prevalence of hypertension and prehypertension between boys and girls. Further studies with larger samples are needed to confirm the epidemiological consistency of the observations made in this study.

Although lower prevalence of hypertension in tribal and rural population is expected, there has been steady increase over time in rural and tribal population as well which may be probably due to rapid urbanization of rural India which has altered the dietary habits, level of physical activity and social pressures in life.

These trends of increasing prevalence of hypertension, prehypertension among traditional tribal population warrants a collective targeted effort in recognizing hypertension and prehypertension in asymptomatic children of all sociocultural backgrounds.

Early identification of at risk children and appropriate lifestyle modification would help in preventing hypertension and its related cardiovascular and cerebrovascular complications.

Competing Interests: None

Funding: Indian council of medical research (ICMR).

Funding: Nil, Conflict of interest: None initiated, Perission from IRB: Yes

\section{References}

1. Mohan B, Kumar N, Aslam N, Rangbulla A, Kumb Karni S, Sood NK et al. Prevalence of sustained hypertension and obesity in Urban and Rural school going children in Ludhiana. Indian Heart J 2004:56: 310 314.
2. Fall $\mathrm{CH}$, Barker DJ. The fetal origins of coronary heart disease and noninsulin dependent diabetes in India. Indian Pediatr. 1997 Jan; 34 (1): 5-8.

3. Vedavati S, Jayashree R, Rafi M. Prevalence of overweight and obesity in affluent adolescent Girls in Chennai in 1981 and 1998. Indian Pediatr 2003; 40: 332336.

4. Narayanappa D, Rajani HS, Mahendrappa KB. Prevalence of Hypertension and Prehypertension Among School Going Children. Karnataka Paediatric Journal Vol. 25, No. 3, 4 July - Dec 2011.86.

5. The fourth report on the diagnosis, evaluation and treatment of high BP in children and adolescents. Pediatrics 2004:114(2):555-575.

6. Bagga A, Jain R, Vijayakumar M, Kanitkar M, Ali U. Evaluation and management of hypertension. Indian pediatr 2007; 44; 103-121.

7. Sarkar SR, Kumar S . Prevalence of hypertension among boys (6-18 years) belonging to Tripuri tribal of Tripura. IJSR Volume: 4 | Issue: 1 | January 2015 .

8. Government of India Census. Website: http:/www. censusindia.gov.in. Accessed 12 Mar, 2009.

9. Kannel WB. Role of blood pressure in cardiovascular disease. The Framingham study. Angiology. 1975 Jan; 26 (1 Pt. 1):1-14.

10. Verma M. Chhatwal J, George SM. Obesity and Hypertension in children. Indian Pediatr. 1994 Sep; 31(9):1065-9.

11. Dressler WW. Modernization, stress, and blood pressure: new directions in research. Hum Biol. 1999 Aug;71(4):583-605.

12. Kusuma YS, Babu BV, Naidu JM. Blood pressure levels among cross-cultural populations of Visakhapatnam district, Andhra Pradesh, India. Ann Hum Biol. 2002 Sep-Oct;29(5):502-12.

13. Nirmala A, Age variation in blood pressure: effect of sex and urbanization in a genetically homogeneous caste population of Andhra Pradesh. American Journal of Human Biology 2001;13(6) :744-752. 
14. Gupta AK, Ahmad AJ. Normal blood pressure and the evaluation of sustained Blood pressure deviation in childhood. Indian Pediatr. 1990 Jan;27(1): 33-42.

15. Sachdev Y. Normal BP and HTN in Indian children. Indian Pediatr. 1984 Jan;21(1):41-8.
16. Narayanappa D, Rajani HS, Mahendrappa KB, Ravikumar VG. Prevalence of Prehypertension and Hypertension among Urban and Rural School Going Children. Indian Pediatr. 2012 Sep;49(9):755-6.

17. Anand NK. Tandon L. Prevalence of HTN in school going children. Indian Pediatr. 1996 May;33 (5):377-81.

\section{How to cite this article?}

Narayanappa, HS Rajani, K Jagadish Kumar, VG. Manjunath. Prevalence of prehypertension and hypertension among jenukuruba tribal children in Mysore district. J PediatrRes.2017;4(01):1-5.doi:10.17511/ijpr.2017.i01.01 